\title{
Contribution for a better understanding of the technological sustainability in electrical energy production through photovoltaic cells
}

\author{
Rui Pedro Mendes, Luís Carrilho Gonçalves ${ }^{1}$ and Pedro Dinis Gaspar ${ }^{1}$ \\ ${ }^{1}$ Electromechanical Engineering Department - Engineering Faculty \\ University of Beira Interior \\ Edifício 1 das Engenharias, Calçada do Lameiro, 6201-001 Covilhã (Portugal) \\ Phone/Fax number:+351967317907, +351275329930/759, e-mail: ruipgmendes@gmail.com, carrilho@ubi.pt, dinis@ubi.pt
}

\begin{abstract}
The conversion of solar energy into electricity reveals a huge importance in the production of "clean" energy, mainly when applied to decentralized production systems (micro-generation). However, there is the need to develop and optimize these processes in order to turn it more sustainable in economic and technological scoops. The main purpose of this work is to study the solar energy conversion into electricity through photovoltaic cells, characterizing the process efficiencies. This study intends to evaluate the energetic and exergetic efficiencies defining them as indicators in the formulation of a sustainability index. All the procedures are in a theoretical scope with an illustrative example in the end of this work.
\end{abstract}

Keywords. Sustainability index, energy, exergy, photovoltaic indicators.

\section{Nomenclature}

$\begin{array}{ll}\boldsymbol{V}_{\boldsymbol{m}} & \text { Maximum Voltage } \\ \boldsymbol{I}_{\boldsymbol{m}} & \text { Maximum Current } \\ \boldsymbol{V}_{\boldsymbol{o c}} & \text { Open circuit Voltage } \\ \boldsymbol{I}_{\boldsymbol{s c}} & \text { Short circuit Current } \\ \boldsymbol{T}_{\boldsymbol{a m b}} & \text { Ambient Temperature } \\ \boldsymbol{T}_{\text {cell }} & \text { Solar cell Temperature } \\ \boldsymbol{A}_{\boldsymbol{c e l l}} & \text { Area of the cell }\left(\boldsymbol{m}^{2}\right) \\ \boldsymbol{h}_{\boldsymbol{c} \boldsymbol{a}} & \text { Convective \& Radiative heat transfer coefficient from } \\ & \text { solar cell to ambient air }\left(\boldsymbol{W} / \boldsymbol{m}^{2} \boldsymbol{K}\right) \\ \boldsymbol{S}_{\boldsymbol{T}} & \text { Solar irradiation }\left(\boldsymbol{W} / \boldsymbol{m}^{2}\right) \\ \boldsymbol{\psi}_{\boldsymbol{P V}} & \text { Exergetic efficiency of photovoltaic system } \\ \boldsymbol{\eta}_{\boldsymbol{P V}} & \text { Energy conversion efficiency of photovoltaic system } \\ \boldsymbol{I} & \text { Solar insolation }\left(\boldsymbol{k W h} / \boldsymbol{m}^{2} / \boldsymbol{y e a r}\right) \\ \boldsymbol{P R} & \text { Performance Ratio }\end{array}$

\section{Introduction}

Searching for a sustainable future, in respect to energy consumption, one has been looking for alternative sources to fossil fuels in useful energy production.

Solar energy conversion trough photovoltaic (PV) panels are one of those sources, which are rising in applications the last years.
Solar irradiation is an inexhaustible source of energy, but not permanently available during the day.

Electricity production trough PV, besides being considered a clean energy conversion process, reveals low efficiencies putting some doubts in its sustainability. Due to these facts, arises the need to characterize this technology, formulating an index to define its sustainability. For that, it is necessary to use indicators to describe the energy conversion process of the technology.

These indicators define the conversion efficiency, the costs associated and the environmental impact.

The exergetic efficiency of PV technology, defines the strongest indicator for the energy conversion process. It gives a more realistic evaluation of how close the real process is following the ideal case. Besides that, its optimization can lead to its sustainability increase. Defined the indicators, the sustainability index can be obtained through a mathematical model given by [2], as it will be explained in the section 3 .

\section{Sustainability concept}

Over the years there have been several definitions of sustainability and still there is not a worldwide acceptable common definition.

To define the sustainability of a process or system, it is necessary to assess the subsystems connected to it, namely environmental, economic, social and technological systems. So, to achieve sustainability, the subsystems balance must be checked within their limits. From a technological point of view, a sustainable development of energy conversion processes results in the consumption of resources that must be available in quantity and in time, avoiding its depletion and with the least negative impact on the environment. Be sustainable determines the rational application of criteria of economic costs in energy conversion/transformation, necessary and adequate technology production to the process and especially in the useful energy acquisition by final consumer.

\section{Sustainability index}

To assess the sustainability of a technological process it must be employed indicators that define and quantify the subsystems involved in the process. For the properties of the system that are not directly measurable, it should be used 
assessment tools in order to obtain their indicators. The exergetic analysis is an example of these tools, very useful in the evaluation of energy conversion processes, being a strong indicator of technology sustainability.

Finally it is necessary to relate all indicators in order to express them in a single value that can quantify the technological process sustainability. This relationship is achieved through a sustainability index formulation using the mathematical expression defined in [2]. It is necessary to assign a membership function, $\boldsymbol{q}\left(\boldsymbol{x}_{\boldsymbol{i}}\right)$ to each $\boldsymbol{x}_{\boldsymbol{i}}$. indicator. For each indicator, we have to:

- choose a maximum and minimum values, respectively, $\boldsymbol{m a x}(\boldsymbol{i})$ and $\boldsymbol{\operatorname { m i n }}(\boldsymbol{i})$

- Indicate whether the function $\boldsymbol{q}\left(\boldsymbol{x}_{\boldsymbol{i}}\right)$ increases or decreases with $\boldsymbol{x}_{\boldsymbol{i}}$, setting a value for the exponent $\lambda$ in order to increase or decrease the $\boldsymbol{q}\left(\boldsymbol{x}_{\boldsymbol{i}}\right)$ function $\boldsymbol{x}_{\boldsymbol{i}}$.

The relationship between the membership function and its indicator can be expressed by:

$$
q\left(x_{i}\right)=\left\{\begin{array}{ccc}
0 & \text { if } & x_{i} \leq \min (i) \\
\left(\frac{x_{i}-\min (i)}{\max (i)-\min (i)}\right)^{\lambda} & \text { if } \min (i)<x_{i} \leq \max (i) \\
1 & \text { if } & x_{i}>\max (i)
\end{array}\right.
$$

The sustainability index $(\boldsymbol{Q})$ is then given by the sum of the all considered indicators considering the weight $\left(\boldsymbol{w}_{\boldsymbol{i}}\right)$ that each one has in the index mathematical expression formulation. The final mathematical expression is then given by:

$$
Q(q ; w)=\sum_{i=1}^{m} w_{i} q_{i}
$$

and considering $\boldsymbol{m}$ indicators for the process characterization.

\section{Exergy}

Exergy is defined as the amount of useful work that can be extracted from a system when brought into equilibrium with the environment through an energy conversion/transformation process. The energy analysis of a process, according to the $1^{\text {st }}$ law of thermodynamics, is based on the energy quantities. The exergetic analysis of a process based on the $1^{\text {st }}$ and $2^{\text {nd }}$ laws of thermodynamics assesses not only the energy quantity but also its quality(or exergy level) on the thermodynamics interaction. It is important to take into account the energy quality, since this quality will be destroyed as the energy passes through conversion/transformation processes and due the irreversibility. The exergetic efficiency gives a more realistic evaluation of the energy conversion/transformation process performance, measuring how the actual process approaches or departs to/from the ideal case.

\section{Exergy and technological sustainability}

The exergetic analysis of a energy conversion/transformation process allows to identify its irreversibility characteristics. The exergy destruction, i.e. the energy that is useless due to its quality decline and the losses to environment in the form of other energy, is proportional to the process irreversibility. Therefore, identifying the irreversibility characteristics one allows to minimize them by reducing exergetic losses and increasing the process exergetic efficiency. Improved exergetic efficiency determines a lower consumption of resources for production of useful energy, leading to lower economic costs associated with the process and to the decreasing of the negative environmental impact. Thus, it can be concluded that the exergy plays an important role in the search for technological sustainability, being the exergetic analysis a rational process in the physical-mathematical formulation of a technological sustainability index.

\section{Indicators for the formulation of a PV technology index}

To characterize the technological sustainability of electricity production through photovoltaic systems, according to a sustainability index, it is necessary to select the indicators that better describe the process. The index value allows us to do a comparative evaluation with other technologies in order to determine the most sustainable.

Some indicators were used for the mathematical modulation of the sustainability index. These indicators characterize the electrical production process from a technological point of view, namely:

$$
\begin{aligned}
& \text { - Exergetic efficiency (1); } \\
& \text { - Greenhouse Gas (GHG) Emissions (2); } \\
& \text { - Electricity Generation Cost (ECE) (3); } \\
& \text { - Electrical Production Efficiency (EPE) (4). }
\end{aligned}
$$

The numbers following the names of these indicators identify them in the index $\boldsymbol{i}$ of the membership function, $\boldsymbol{q}_{\boldsymbol{i}}$ and indicator $\boldsymbol{x}_{\boldsymbol{i}}$. The exponent $\lambda$ takes the values 1 or -1 if $\boldsymbol{q}_{\boldsymbol{i}}$ is increasing or decreasing with the increase of $\boldsymbol{x}_{\boldsymbol{i}}$, respectively.

\subsection{Exergetic efficiency}

This indicator is based on the exergetic assessment of the PV cell at a thermodynamic level. The exergetic efficiency of a $\mathrm{PV}$ cell is given by [6]:

$$
\psi_{P V}=\frac{V_{m} I_{m}-\left(1-\frac{T_{a m b}}{T_{\text {cell }}}\right)\left[h_{\text {ca }} A_{\text {cell }}\left(T_{\text {cell }}-T_{\text {amb }}\right)\right]}{\left(1-\frac{T_{a m b}}{T_{\text {sun }}}\right) S_{T} A_{\text {cell }}}
$$

For a minimum value we will consider an exergetic efficiency of $1 \%$ assuming that values below that are no useful. For a maximum value we choose the exergetic efficiency for a reversible case. This one can be obtained by the ratio of electrical exergy (4) and solar irradiation (5). These last expressions are given by [6]

$$
\text { Ex } \boldsymbol{x}_{\text {electrical }}=\boldsymbol{V}_{o c} I_{s c}
$$

$$
E x_{\text {solar }}=\left(1-\frac{T_{a m b}}{T_{s u n}}\right) S_{T} A_{c e l l}
$$

$$
\psi_{\max }=\frac{V_{o c} I_{s c}}{\left(1-\frac{T_{a m b}}{T_{\text {sun }}}\right) S_{T} A_{c e l l}}
$$


The membership function $\boldsymbol{q}_{\mathbf{1}}$ grows as the indicator increases, being this indicator expressed by the following parameters:

$$
\begin{gathered}
x_{1}=\psi_{P V} \\
\min (1)=0,01 \\
\max (1)=\psi_{\max } \\
\lambda_{1}=1
\end{gathered}
$$

\subsection{Greenhouse Gas (GHG) emissions}

The greenhouse effect has increased due to excessive emissions of toxic gases from energy conversion/transformation and consumption. For a technology to be sustainable, these emissions have to be minimal in order to preserve the environment.

Emissions associated with PV cells are mainly due to fossil fuels used in their manufacture, as during its operation there are no GHG emissions. According to [9] and [8], a PV cell GHG emission is quantified by expression (7).

$$
\begin{array}{r}
\mathrm{GHG}\left(\mathrm{gCO}_{2} / \mathrm{kWh}\right) \\
=\frac{\mathrm{CO}_{2} \text { emissions Through LCA }}{E \times S \times P R \times \text { Lifetime }(\text { years })}
\end{array}
$$

The denominator expresses the electricity generated during the life cycle of the PV cell.

The minimum limit for this indicator will be for the ideal case, $0 \boldsymbol{g C O}_{2} / \boldsymbol{k W h}$. This will be the theoretical situation. As a maximum we will consider $500 \mathbf{g C O}_{2} / \boldsymbol{k W h}$, which is the value agreed and voted by the European Parliament's environment committee to all coal power plants built after 2015.Technologies with bigger emission values can be consider, at the moment not sustainable.

The membership function will decrease when the indicator increase.

For GHG emissions we suggest the following parameters.

$$
\begin{gathered}
x_{2}=G H G \\
\min (2)=0\left(g C O_{2} / k W h\right) \\
\max (2)=500\left(g C O_{2} / k W h\right) \\
\lambda_{2}=-1
\end{gathered}
$$

\subsection{Electricity Generation Cost (EGC)}

PV cells have no costs for the primary energy consumption of electricity production, since this energy comes from solar radiation. However, as solar radiation is not always permanently available during the day, the maintenance costs of PV systems have a great influence on the price of the electricity generated. The Electricity Generation Cost (EGC) is defined as the economic cost per unit of energy produced inside the EU. According to [9] this value can be estimated by expression (8).
For this case, the maximum and minimum values depend on electricity market, and will not be considered here.

$$
\begin{aligned}
& E G C \\
& =\frac{\text { Annual expenses of the system }(€ / \text { year })}{\text { Annual electricity generation }(\text { kWh } / \text { year })}
\end{aligned}
$$

$$
\begin{gathered}
x_{3}=E G C \\
\lambda_{3}=-1
\end{gathered}
$$

\subsection{Electricity Production Efficiency (EPE)}

The electricity production efficiency (EPE) according to [15] is calculated as the ratio of energy generated by the PV cell during its life cycle $\left(\boldsymbol{E}_{\text {ger }}\right)$ to the sum of different energy components used for the manufacture $\left(\boldsymbol{E}_{\boldsymbol{f} a \boldsymbol{b}}\right)$, the installation $\left(\boldsymbol{E}_{\text {ins }}\right)$, the operation and maintenance $\left(\boldsymbol{E}_{\boldsymbol{o} \& \boldsymbol{m}}\right)$ during its life cycle and for recycling $\left(\boldsymbol{E}_{\text {rec }}\right)$. EPE is expressed by the equation (8).

$$
E P E=\frac{E_{g e r}}{E_{f a b}+E_{\text {ins }}+E_{o \& m+} E_{r e c}}
$$

This is an important indicator for PV technology in comparison with other technologies as it balances its assessment with the others.In order that a technology to be sustainable, the EPE value must be greater than 1 . For a situation in which EPE is equal to unity, this means that the electricity produced during the life cycle covers the energy used to manufacture the PV cell. Any value below the unit makes the technology not sustainable. According to [15] due to the fact that lifespan of PV systems extends to 50 years resulting on a EPE of 9.5, one considers this value as the maximum for this indicator.

The following parameters can be suggested:

$$
\begin{gathered}
x_{4}=E P E \\
\min (3)=1 \\
\max (3)=9.5 \\
\lambda_{4}=1
\end{gathered}
$$

\section{Formulation of a PV technology index}

For the formulation of the sustainability index is necessary to assign a weight coefficient to each indicator. Despite all the above indicators being relevant in the PV technology sustainability, the exergetic efficiency will have the greatest weight coefficient. This is because higher exergetic efficiency influences the other indicators in a favourable direction for sustainability. The other indicators will be evaluated with equal weight coefficients. Therefore, the weight coefficient of each indicator varies between 0 and 1 , and their sum equals unity. Thus, the sustainability index will always vary between 0 and 1 , as expected. 
Table 1

Weight-coefficient proposed values

\begin{tabular}{|c|c|}
\hline Weight & Value \\
\hline $\boldsymbol{w}_{\mathbf{1}}$ & 0,55 \\
\hline $\boldsymbol{w}_{\mathbf{2}}$ & 0,15 \\
\hline $\boldsymbol{w}_{\mathbf{3}}$ & 0,15 \\
\hline $\boldsymbol{w}_{\mathbf{4}}$ & 0,15 \\
\hline Total & 1 \\
\hline
\end{tabular}

The membership function of each indicator is given by the functional relation (1), obtaining the values of $\boldsymbol{q}_{\mathbf{1}}, \boldsymbol{q}_{\mathbf{2}}, \boldsymbol{q}_{\mathbf{3}}$ and $\boldsymbol{q}_{4}$.

The sustainability index is then given by the mathematical expression (2).

$$
\begin{aligned}
Q(q ; w) & =\sum_{i=1}^{4} w_{i} q_{i} \\
= & 0,55 q_{1}+0,15 q_{2}++0,15 q_{3}+0,15 q_{4}
\end{aligned}
$$

\section{Ilustrative example}

This section pretends to do an exemplification of the procedure to calculate the exergy efficiency indicator.

Three types of PV modules are evaluated with the aim to characterize their exergetic efficiency.

The three types of PV modules are built with the following materials: mono-crystalline silicon $(\mathrm{Si})$, poly-crystalline silicon(p-Si) and amorphous silicon(a-Si). The data provided is obtained from the SUNTECH Datasheets (Table 3). A Standard Temperature Condition (STC) is considered for the exergetic efficiency calculation. The radiative component of heat transfer coefficient was not considered. The convective component is calculated from an empirical expression given by [16] according to STC. The value obtained was $9,5 \boldsymbol{W} / \boldsymbol{m}^{2} \boldsymbol{K}$. The exergetic efficiencies (Table 4) are determinated with the expression (3). Using the maximum and minimum values established, the membership function of each cell is obtained and the values are expressed in Table 5.

Table 2

STC Conditions.

\begin{tabular}{|c|c|}
\hline Ambient Temperature & $25^{\circ} \mathrm{C}$ \\
\hline Solar Irradiation & $1000 \mathrm{~W} / \mathbf{m}^{\mathbf{2}}$ \\
\hline Wind Speed & $1 \mathrm{~m} / \mathbf{s}$ \\
\hline
\end{tabular}

Table 3

PV Cell Data.

\begin{tabular}{|c|c|c|c|}
\hline Parameters & $\begin{array}{c}\mathbf{S i} \\
\text { STP185S-24/Ad }\end{array}$ & $\begin{array}{c}\mathbf{p - S i} \\
\text { STP280-24/Ad }\end{array}$ & $\begin{array}{c}\mathbf{a - S i} \\
\text { STPO90Ts-AA }\end{array}$ \\
\hline Power $(\boldsymbol{W})$ & 185 & 270 & 86 \\
\hline $\boldsymbol{V}_{\boldsymbol{m}}(\boldsymbol{V})$ & 36,4 & 35,2 & 73,12 \\
\hline $\boldsymbol{I}_{\boldsymbol{m}}(\boldsymbol{A})$ & 1,23 & 7,95 & 1,23 \\
\hline $\boldsymbol{V}_{\boldsymbol{o c}}(\boldsymbol{V})$ & 45 & 44.8 & 93,8 \\
\hline $\boldsymbol{I}_{\boldsymbol{s c}}(\boldsymbol{A})$ & 5,4 & 35.2 & 1,5 \\
\hline $\boldsymbol{A}_{\boldsymbol{c e l l}}\left(\boldsymbol{m}^{\mathbf{2}}\right)$ & 1,27 & 1,94 & 1,43 \\
\hline NOCT $\left({ }^{\circ} \mathbf{C}\right)$ & 45 & 45 & 45 \\
\hline $\boldsymbol{T}_{\boldsymbol{c e l l}}\left({ }^{\circ} \mathrm{C}\right)$ & 56,25 & 56,25 & 56,25 \\
\hline
\end{tabular}

Table 4

Exergetic Efficiency.

\begin{tabular}{|c|c|c|c|}
\hline $\begin{array}{c}\text { Exergetic } \\
\text { efficiency }\end{array}$ & $\mathbf{S i}$ & $\mathbf{p - S i}$ & $\mathbf{a - S i}$ \\
\hline $\boldsymbol{\psi}_{\boldsymbol{P V}}(\%)$ & 4,49 & 1,91 & 3,65 \\
\hline
\end{tabular}

Table 5

Indicator Parameters for Exergy Efficiency.

\begin{tabular}{|c|c|c|c|}
\hline Parameters & $\mathbf{S i}$ & $\mathbf{p}-\mathbf{S i}$ & $\mathbf{a}-\mathbf{S i}$ \\
\hline $\boldsymbol{m i n}$ & 0.01 & 0.01 & 0.01 \\
\hline $\boldsymbol{m a x}$ & 0.057 & 0.2028 & 0.1035 \\
\hline $\boldsymbol{x}$ & 4,49 & 1,91 & 3,65 \\
\hline $\boldsymbol{\lambda}$ & 1 & 1 & 1 \\
\hline $\boldsymbol{q}$ & 0.7 & 0.04 & 0.2834 \\
\hline
\end{tabular}

\section{Discussions}

The scope of this work is to demonstrate a mathematical procedure for a sustainability index formulation applied to electricity production trough PV cells. It is explained the great role of exergy in technologic sustainability as indicator. Other indicators are suggested as important choices to the index construction. An exergetic efficiency characterization of PV cell is performed as an illustrative example. Although, this example do not correspond to reality, besides based on real data. In future, this procedure will be applied to a real PV micro-generation system in order to define its sustainability with the mathematical model described along this work.

\section{References}

[1] Ibrahim Dincer, Marc A. Rosen, Exergy, Energy, Environment and sustainable development, 2007

[2] K. Hanjalic, R. van de Krol, A. Lekic, Sustainable Energy Technologies, Options and Prospects, 2008 Springer

[3] Felix A. Farret, M. Godoy Simões, Integration of alternative sources of energy, 2006

[5] Ibrahim Dincer, Exergetic and sustainable aspects of green energy systems, Clean 2007 35(4),311-322, Wiley-Inter science

[6] Anand S.Joshi, Ibrahim Dincer, and K. Bale V. Reddy, "Termodynamic assessment of photovoltaic systems", Solar Energy 93 1139-1149, 2009.

[7] M. Ito, K. Kato, K. Komoto, T. Kichimi, and K. Kurokawa, "A Comparative Study on Cost and Life-cycle Analysis for 100MW Very Large-scale PV (VLS-PV) Systems in Deserts Using m-Si, a-Si, CdTe, and CIS Modules", John Wiley \& Sons, 2007.

[8] V. M. Fthenakis, H. C. Kim, and E. Alsema, "Emissions from Photovoltaic Life Cycles", Environmental Science \& Tecnology, vol. 42, no. 6, 2008. 
[9] Varun, R. Prakash, and K. Bhat, "Energy, economics and environmental impacts of renewable energy systems", Elsevier, Renewable and Sustainable Energy Reviews 13, 2009.

[10] M. Raugei, and P. Frankl, "Life cycle impacts and costs of photovoltaic systems: Current state of the art and future outlooks", Elsevier, Energy 34, 2009.

[11] R. Kannan, K.C. Leong, R. Osman, H.K. Ho, and C.P. Tso, "Lide cycle assessment study of solar PV system: Na example of a $2.7 \mathrm{~kW}_{\mathrm{p}}$ distributed solar PV system in Singapure", Elsevier, Solar Energy 80, 2006.

[12] M. Kanoglu, I. Dincer, Y.A. Cengel, "Exergy for better environment and sustainability", Springer Science+Business Media B.V. 2008.

[13] A.F. Sherwani, J.A. Usmani, and Varun, "Life cycle assessment of solar PV based electricity generation systems: A review", Elsevier, Renewable and Sustainable Energy Reviews 14, 2010.

[14] A. Evans, V. Strezov, and T.J. Evans, "Assessment of sustainability indicators for renewable energy tecnologies", Elsevier, Renewable and Sustainable Energy Reviews 13, 2009.

[15] Christopher Koroneos, Nikolaos Stylos and Nicolas Moussipoulos, "LCA of Multicrystaline Silicon Photovoltaics Systems”, LCA Case Studies, Photovoltaic Systems Part I, 129136, 2006

[16] J. Martí-Herrero and M.R. Heras-Celemin," Dynamic thermal simulation of a solar chimney with PV modules", International Conference "Passive and Low Energy Cooling for the Built Environment", 891, May 2005 